\title{
Spatial correlation in the ambient core noise field of a turbofan engine
}

\author{
Jeffrey Hilton Miles ${ }^{\text {a) }}$ \\ NASA John H. Glenn Research Center at Lewis Field, Cleveland, Ohio 44135
}

(Received 18 November 2011; revised 18 April 2012; accepted 22 April 2012)

An acoustic transfer function relating combustion noise and turbine exit noise in the presence of enclosed ambient core noise is investigated using a dynamic system model and an acoustic system model for the particular turbofan engine studied and for a range of operating conditions. Measurements of cross-spectra magnitude and phase between the combustor and turbine exit and auto-spectra at the turbine exit and combustor are used to show the presence of indirect and direct combustion noise over the frequency range of $0-400 \mathrm{~Hz}$. The procedure used evaluates the ratio of direct to indirect combustion noise. The procedure used also evaluates the post-combustion residence time in the combustor which is a factor in the formation of thermal $\mathrm{NO}_{x}$ and soot in this region. These measurements are masked by the ambient core noise sound field in this frequency range which is observable since the transducers are situated within an acoustic wavelength of one another. An ambient core noise field model based on one and two dimensional spatial correlation functions is used to replicate the spatially correlated response of the pair of transducers. The spatial correlation function increases measured attenuation due to destructive interference and masks the true attenuation of the turbine.

[http://dx.doi.org/10.1121/1.4714359]

PACS number(s): 43.60.Ac, 43.28.Kt, 43.55.Br, 43.55.Cs [SAF]

Pages: $4625-4639$

\section{NOMENCLATURE}

$B_{e} \quad$ Effective resolution bandwidth, $B_{e}=1 / T_{d}=r_{s} / N$, $2 \mathrm{~Hz}$

C Cost function

$f_{u} \quad$ Upper frequency limit, $f_{u}=1 / 2 \Delta t=r_{s} / 2, \mathrm{~Hz}(32$ $768 \mathrm{~Hz}$ )

$\hat{G}_{x, x}(f) \quad$ Estimated input signal one-sided auto spectral density function

$\hat{G}_{x, y}(f)$ Estimated one-sided cross-spectral density function

$\hat{G}_{y, y}(f) \quad$ Estimated output signal one-sided autospectral density function

$H(f) \quad$ Frequency response (transfer) function

$K$ Turbine attenuation or producton/creation factor, $\epsilon_{2}$

$N$ Segment length, number of samples per segment, $N=r_{s} T_{d},(32768)$

$N_{d} \quad$ Direct combustion noise signal system noise

$N_{i} \quad$ Indirect combustion noise signal system noise

$N_{T} \quad$ Tailpipe signal system noise

$n_{o} \quad$ Number of segments/blocks with 50 percent overlap, $n_{o}=2 B_{e} T_{\text {total }} \approx 273$

$n_{s} \quad$ Number of disjoint (independent) segments used in spectra estimates, $n_{s}=B_{e} T_{\text {total }} \approx 128$

$r_{m} \quad$ Microphone separation

$r_{s} \quad$ Sample rate, samples/s (65 536)

$S$ Cost function sums

$T_{\text {total }} \quad$ Total record length, $T_{\text {total }}=n_{s} T_{d}, \mathrm{~s}(\approx 70 \mathrm{~s})$

$T_{d} \quad$ Record length of segment, $T_{d}=N / r_{s}, 0.5 \mathrm{~s}$

\footnotetext{
a) Author to whom correspondence should be addressed. Electronic mail: Jeffrey.H.Miles@nasa.gov
}

$U_{x, y}(f) \quad$ Aligned cross-spectral density function

$x(t) \quad$ Input signal from combustor pressure sensor CIP1

$y(t) \quad$ Output signal from turbine exit pressure sensor

10 Turbine exit signal, T551

11 Turbine exit signal, T552

9 Combustor probe signal, CIP1

c Core

$d$ Direct combustion noise

e Effective

$i \quad$ Indirect combustion noise

$o$ Zero frequency

pc Post-combustion

TE Turbine exit

$x \quad$ Input signal

$y \quad$ Output signal

$\alpha_{c 1}, \alpha_{c 2}$ One dimensional core noise spatial correlation coefficient level constant, $\epsilon_{8}, \epsilon_{11}$

$\alpha_{T E} \quad$ Two dimensional turbine exit noise spatial correlation level constant, $\epsilon_{6}$

$\beta \quad$ Angle of incident plane wave to a pair of sensors

$\Delta t \quad$ Sampling interval, $\Delta t=1 / r_{s} \mathrm{~s}$

$\epsilon$ Model parameter

$\eta \quad$ Two dimensional turbine exit noise spatial correlation coefficient function

$\nu \quad$ Ratio of contribution of direct combustion noise to indirect combustion noise, $\epsilon_{1}$

$\rho(f)$ Spatial correlation for two separated turbofan engine core pressure sensors

$\tau_{o} \quad$ Indirect combustion noise time delay alignment, $3.05 \mathrm{~ms}$

$\tau_{A} \quad$ Acoustic wave travel time between sensors, ms

$\tau_{c 1}, \tau_{c 2}$ One dimensional core noise spatial correlation coefficient time constant, $\epsilon_{9}, \epsilon_{12}$, ms 


\begin{tabular}{|c|c|}
\hline$\tau_{p c}$ & Post-combustion residence time, $\epsilon_{4}$, ms \\
\hline$\tau_{T E}$ & $\begin{array}{l}\text { Two dimensional turbine exit noise spatial corre- } \\
\text { lation time constant, } \epsilon_{7}, \mathrm{~ms}\end{array}$ \\
\hline$\tau_{T}$ & Turbine frequency response time constant, $\epsilon_{3}, \mathrm{~s}$ \\
\hline$\varphi$ & Post-combustion residence time phase shift, deg \\
\hline$\varphi_{o}$ & $\begin{array}{l}\text { Zero frequency post-combustion residence time } \\
\text { phase shift, } \epsilon_{5}, \mathrm{deg}\end{array}$ \\
\hline$\vartheta_{c_{1}}, \vartheta_{c_{2}}$ & $\begin{array}{l}\text { Zero frequency one dimensional core noise spatial } \\
\text { correlation coefficient phase shift, } \epsilon_{10}, \epsilon_{13} \text {, deg }\end{array}$ \\
\hline$\zeta_{1}, \zeta_{2}$ & $\begin{array}{l}\text { One dimensional core noise spatial correlation } \\
\text { coefficient function }\end{array}$ \\
\hline$A$ & Acoustic \\
\hline$E$ & Estimated \\
\hline$M$ & measured \\
\hline
\end{tabular}

\section{INTRODUCTION}

Low frequency noise generated in the turbofan engine core by direct and indirect combustion noise may make a significant contribution to the overall noise signature in the aft direction at the low power settings used on an airport flight trajectory. In addition, low frequency core noise may also be a problem for future aircraft using lean-burning ultra-low-emissions combustors. The results of using pressure sensor measurements in a turbofan engine combustor and at the turbine exit to determine a low frequency acoustic linear system transfer function relating the turbine exit noise to the combustion noise are reported here. The linear system transfer function model is enhanced by a spatial acoustic correlation function between the sensors in order to account for the enclosure sound field. Because proprietary geometry and flow information is not available, the method used avoids the usual limitation imposed by the need to know the exact geometry and flow conditions in the engine core to account for the acoustics of the enclosure. The approach used is based on an approximate analytical formulation. In the frequency range studied, indirect combustion noise is separated from direct combustion noise since it has a phase relationship to direct combustion noise characterized by a post-combustion (post-flame) residence time delay.

Two possible low frequency turbofan engine noise sources are "direct" and "indirect" combustion noise. The source of combustion noise attributed to the unsteady pressures produced by the unsteady combustion process that propagate at the speed of sound through the turbine to the far field is called the "direct" combustion noise source. The generation of direct combustion noise from a open non-premixed turbulent flame is discussed by Ihme and Pitsch. ${ }^{1}$ The generation of direct combustion noise in a combustor is discussed by Liu et $a .^{2}$ The other source of turbofan engine combustion noise is known as the "indirect" mechanism in which the noise is generated in the turbine by the interaction of entropy fluctuations, which also originate from the unsteady combustion process but propagate at the flow velocity. Noise is generated as entropy fluctuations propagate through regions characterized by mean flow velocity gradients or pressure gradients in the turbine stages. A summary of early references using "actuator disc" theory to study turbine generated indirect combustion noise is given by Cumpsty. ${ }^{3}$ Bodony presents computational and analytical results on the interaction of a convected entropy disturbance with an air-foil shaped body. ${ }^{4}$ A related topic is the noise generated by propagation of an entropy disturbance through a nozzle considered theoretically by Marble and Candel, ${ }^{5}$ Leyko et al., ${ }^{6}$ and Howe. ${ }^{7}$ Experimental studies of indirect combustion noise generated by flow of an entropy disturbance through a nozzle have been conducted by Bake et al. ${ }^{8}$ and Rausch et al. ${ }^{9}$ A theoretical study of the generation of indirect combustion noise in an auxiliary power unit (APU) has been conducted by $\mathrm{Xu}$, Tam, and Parrish. ${ }^{10}$ Combustion chamber instability can be caused by a feedback mechanism which couples combustion chamber acoustics with convectively transported fluctuations of entropy as noted by Polifke, Paschereit and Döbbeling. ${ }^{11}$

Investigations of indirect and direct turbofan engine noise in the far field were conducted by turbofan engine companies with NASA sponsorship. Experimental studies of indirect combustion noise from a Pratt \& Whitney PW4098 (East Hartford, CT) turbofan engine using an aligned and purposely nonaligned coherence procedure on acoustic measurements in the engine combustor and in the far field are discussed by Miles. ${ }^{12,13}$ Experimental studies of indirect combustion noise from a Honeywell TECH977 (Phoenix, AZ) turbofan engine using cross-spectra and correlation function procedures to estimate the post-combustion (postflame) residence time from acoustic measurements in the engine combustor and in the far field are discussed by Miles. ${ }^{14-17}$ The post-combustion (post-flame) residence time is the time taken for an entropy disturbance to travel in the combustor from the flame to the turbine entrance at the flow velocity. These studies showed indirect combustion noise was present in these turbofan engines at low frequencies.

The relative importance of direct and indirect combustion noise mechanisms in creating core noise in modern engines and future engines is unknown. In addition, the fundamental combustion noise prediction capability of the NASA Aircraft Noise Prediction Program (ANOPP) is based on physical models attributing the core noise to direct combustion noise. In order to assess and improve the NASA combustion noise prediction capability, noise source separation studies using pressure sensors in the combustor and at the turbine exit have been made by Hultgren and Miles. ${ }^{18}$ Hultgren ${ }^{19}$ used noise separation signal processing techniques with three engine-internal sensors to determine the turbine transfer function. Hultgren ${ }^{19}$ also suggested an improvement for the direct combustion-noise module in ANOPP.

A lot of research on topics related to direct and indirect combustion noise has been performed without examination of turbofan engine core acoustic measurements to study direct and indirect combustion noise as generated in a turbofan engine. As a step toward improving the understanding of the acoustics in the combustor-turbine system, an acoustic linear system transfer function model relating direct and indirect combustion noise and the turbine exit noise in the presence of ambient core noise is reported here for a range of operating conditions. Using two engine-internal sensors from the same test program studied by Hultgren, ${ }^{19}$ the combustor and turbine exit auto-spectra and the combustor/ 
turbine cross-spectra are calculated and are used in developing the transfer function model reported here. The original model was based on an acoustic linear system transfer function between the combustion noise and the turbine exit noise and did not take into account the effect of the enclosure. The result was a noticeable gap between the measurements and the model results. The advance demonstrated here is that by providing an enclosure sound field based on spatial correlation in the engine core using an approximate analytical formulation, the resulting model is in improved agreement with measured acoustic cross-spectra phase. The results presented by Hultgren ${ }^{19}$ do not account for an ambient enclosure sound field based on spatial correlation in the engine core. This paper shows that by including an ambient enclosure sound field the large scale distortion observed in the cross-spectrum phase angle can be replicated. In addition, by including an ambient enclosure sound field the reduction in the measured auto and cross-spectrum amplitude at low frequencies is also replicated. These results are of minor consequence to the conclusions drawn by Hultgren. ${ }^{19}$ However, they radically complicate any simple approach one might propose to investigate the relation between combustion noise and noise at the turbine exit that is based on comparing calculated results with measurements.

In order to gain physical insight into combustion noise, auto and cross spectra measurements made using a pressure sensor in the combustor and pressure sensors at the turbine exit have been studied to determine how much noise at the turbine exit is due to indirect combustion noise and how much noise is due to direct combustion noise. In addition, the cross-spectrum phase angle slope can provide information on the post-combustion residence time in the combustor which is a factor in the formation of thermal $\mathrm{NO}_{x}$ and soot in this region. Unfortunately, the low frequency measurements are made in a confined space and the measured auto spectra at the turbine exit and the cross-spectra are masked by an interference pattern due to the ambient sound field which can be measured because the pressure sensors are situated within an acoustic wavelength of one another. The core noise pair of sensors are within an acoustic wavelength of one another and behave in a manner similar to a pair of sensors in the ocean or in a diffuse sound field in a reverberant room or wind tunnel when a pair of sensors in these venues are within an acoustic wavelength of one another. ${ }^{20-26}$ One dimensional and two dimensional spatial correlation function models are used to study the correlated responses of the transducers to the ambient acoustic core noise field. The development of a simple physical model for the transfer function lead to the discovery of spatial correlation in the enclosed ambient core noise field.

Turbine noise was studied extensively in the 1970s. Studies were conducted on the topic of turbine tone generation. Other studies deal with the topic of attenuation of direct combustion noise. The topic of indirect combustion noise was studied analytically and in model scale tests. Indirect combustion noise was not thought to be an important contributor to turbofan engine core noise. Consequently, experimental studies of indirect combustion noise in turbofan engines were not conducted in this time period. Presently, as a result of previous studies, core noise from turbofan engines is treated as being due to such individual sources as the compressor, combustor, and turbine. The turbine in previous analytical and experimental studies has been treated as a device that attenuates the direct combustion noise with an attenuation constant that depends only on the turbofan engine operation parameters such as the pressure and temperature at the inlet and exit of the turbine and not on frequency. Stone, Krejsa, and Clark $^{27}$ discuss the current status core noise modeling for turbofan engines and provide a historical perspective.

The net travel time of the indirect combustion noise signal from the combustor to the far field is increased since the travel velocity of the entropy fluctuations to the turbine is the flow velocity in the combustor. This flow velocity is a small fraction of the speed of sound. Miles et al. ${ }^{28,29}$ have shown that the pressure and entropy should be in phase in the combustor. Consequently, one might expect that the pressure signal from an indirect combustion noise source would be delayed relative to a pressure signal from a direct combustion noise source since an indirect combustion noise signal does not travel with the speed of an acoustic wave until it interacts with the turbine. Miles ${ }^{14-16}$ with data from the Honeywell TECH 977 engine test program shows that the cross-spectra and correlation function between a combustor sensor and far-field microphones are tools that provide a way to separate "direct" and "indirect" coherent combustion noise due to this travel delay time. This paper uses measurements in the combustor and at the turbine exit from the Honeywell TECH 977 engine test program. This paper uses tools that are part of signal-processing theory to study a combustor pressure sensor signal and a turbine exit pressure sensor signal. The cross-spectral density phase measurement identifies a time delay that corresponds to the convective time delay which identifies the presence of indirect combustion noise. This time delay is the post-combustion residence time in the combustor which is a factor in the formation of thermal $\mathrm{NO}_{x}$ and soot in the post-combustion zone in the combustor. The coherence between the two sensors identifies the spectral region of importance to indirect combustion noise to being in the $0-400 \mathrm{~Hz}$ frequency range. This paper discusses the cross-spectral density phase angle and the coherence.

The investigation in this paper covers the frequency range below $400 \mathrm{~Hz}$ and not the turbine tone source region in the range of 3 to $9 \mathrm{kHz}$ which has been studied experimentally by Enghardt et al..$^{30}$ and computationally by Van Zante and Envia. ${ }^{31}$ In addition, compressor noise is above the $400 \mathrm{~Hz}$ frequency range $\mathrm{e}^{32}$ and does not contribute in the frequency range considered.

This source identification problem is similar to the parameter or system identification problem. Most recent standard treatments of system identification problems use the time domain and lump together linear and nonlinear system treatments. These modern methods can account for changes in dynamics as a function of excitation amplitude. Unfortunately, procedures discussed assume one has control of the system input signals so one can study system response to different amplitudes. This ability is not generally available for a turbofan engine noise source study because abrupt changes 
or perturbations introduced might for example modify the pattern factor which describes the spatial temperature distribution across the turbine blades. This can cause enough stress on rapidly rotating blades to create turbine blade stress fractures and destroy the engine. In addition, these modern methods do not cover systems with time delays, such as the convective time delay connected with the indirect combustion noise. As an alternative, one approach is to create a linear model approximation that can be considered to be the first term in a series of functions that would include nonlinear effects. This approach is applied herein by providing a linear model at each system operating point. This will be discussed next.

Conveniently, an earlier parameter identification method for a linear system based on minimizing a cost function based on the error between a measured transfer function and a model transfer function which is described, for example, by Sanathanan and Koerner ${ }^{33}$ is available. Miles ${ }^{34}$ used this frequency domain type approach of minimizing a quadratic cost function based on the error between a measured boiler transfer function and a model boiler transfer function to model a system with a time delay and a similar type of approach is used on the system identification problem discussed in this paper.

In the next section the engine noise data are presented. Then the linear system theory will be discussed. Next, the acoustic spatial correlation model used herein to account for the enclosure will be presented. Then, results are presented and discussed. Finally, some conclusions are presented.

\section{ENGINE NOISE DATA AND ANALYSIS}

The engine test program and preliminary data analysis are described next.

\section{A. Engine test data}

The NASA/Honeywell static engine test program was conducted at Honeywell's San Tan outdoor acoustic test facility using a Honeywell TECH977 engine (Fig. 1) and the results are described in a report by Weir. ${ }^{35}$ The dual-spool, turbofan engine has a direct drive, wide chord fan connected by a long shaft to the low-pressure turbine spool and a highpressure compressor connected by a concentric short shaft to the turbine high-pressure spool. The fan diameter is $34.2 \mathrm{in}$. The combustor design is a straight-through-flow annular geometry with 16 fuel nozzles and 2 igniters. Data obtained for one configuration in the test program are analyzed in this pa-

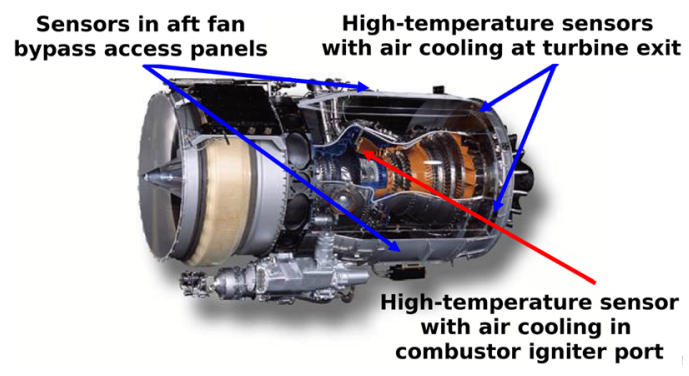

FIG. 1. (Color online) Honeywell TECH977 engine.
TABLE I. Spectral estimate parameters.

\begin{tabular}{lc}
\hline \hline Parameter & Value \\
\hline Segment length (data points per segment), $N$ & 32768 \\
Sample rate, $r_{s}$, samples $/ \mathrm{s}$ & 65536 \\
Segment length, $T_{d}=N / r_{s}, \mathrm{~s}$ & 0.500 \\
Sampling interval, $\Delta t=1 / r_{s}, \mathrm{~s}$ & $1 / 65536$ \\
Bandwidth resolution, $B_{e}=\Delta f=1 / T_{d}=r_{s} / N, \mathrm{~Hz}$ & 2.0 \\
Upper frequency limit, $f_{u}=1 / 2 \Delta t=r_{s} / 2, \mathrm{~Hz}$ & 32768 \\
Number of independent samples, $n_{s}$ & 128 \\
Overlap & 0.50 \\
Sample length, $T_{\text {total }, \mathrm{s}}$ & $\approx 70$ \\
\hline \hline
\end{tabular}

per. The engine-internal instrumentation in this configuration included high-temperature pressure sensors with air cooling in a combustor igniter port identified herein as CIP1 (sensor 9) and at the turbine exit sensors identified as T551 (sensor 10) and T552 (sensor 11). Pressure time histories for the T551 turbine exit sensor are used herein.

The data acquisition system had a sampling rate of 65 $536 \mathrm{~Hz}$ and a sampling duration of roughly $70 \mathrm{~s}$. The spectra were calculated using a 50 percent overlap. This permitted data reduction using $\approx 254$ overlapped ensemble averages at a bandwidth resolution of $2 \mathrm{~Hz}$. Further signal estimation parameters are shown in Table I.

\section{B. Combustor-turbine exit acoustics}

All the spectra and cross-spectra are estimated using Welch's nonparametric method which is based on averaging multiple windowed periodograms using overlapping time sequences. $^{36,37}$ Using these spectra and cross-spectra, the magnitude squared coherence is calculated to measure the similarity of the amplitude variations at particular frequencies. The ^ accent will be used to denote the statistical basis of a variable. This is done to avoid confusion with calculations of coherence using a single segment or block which yield a coherence of unity.

The post-combustion (post-flame) residence time delay due to convection of entropy at the flow speed in the combustor identified by Miles ${ }^{14,15}$ also shows up in combustor sensor signal/turbine exit signal cross-spectrum phase angle plots. Based on the slope of the phase angle plot shown in Fig. 2, the time delay is slightly greater than $3.05 \mathrm{~ms}$. In this paper, in order to study the enclosure sound field, the time

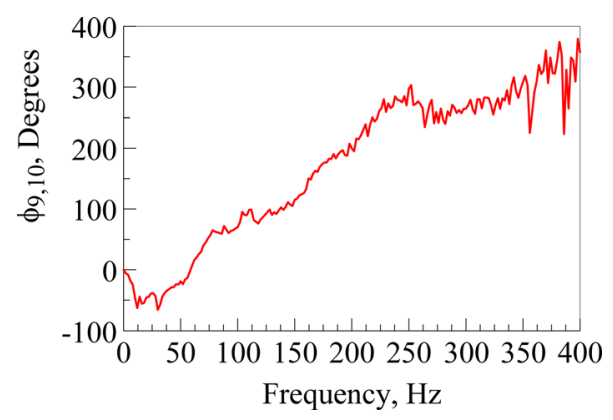

FIG. 2. (Color online) Cross-spectrum phase angle between combustor and turbine exit signal in a turbofan engine at 48 percent maximum power (flight idle) using sensors CIP1(9) and T551(10) as measured (unwrapped). 
delay is reduced by properly aligning the time histories by 200 time steps or about $3.05 \mathrm{~ms}(3.05176 \mathrm{~ms}$ $=200 \times 1000 / 65536$ ). The alignment is used to reveal in more detail the interference pattern in the phase angle plots created by spatial correlation in the ambient sound field at low frequencies. The transfer function will be identified using the aligned signal cross-spectra.

The combustor sensor signal/turbine exit signal magnitude squared aligned coherence (MSC) function is shown in Fig. 3 for the 48 percent maximum power case. Plots using a linear and logarithmic MSC function scale are presented. The MSC function is given by

$$
\hat{\gamma}_{x, y}^{2}=\frac{\left|\hat{G}_{x, y}\right|^{2}}{\hat{G}_{x, x} \hat{G}_{y, y}} .
$$

Also shown in Fig. 3(b) are coherence thresholds calculated from

$$
\hat{\gamma}_{x_{n} x_{n}}^{2}\left(n_{s}\right)=1-(1-P)^{1 /\left(n_{s}-1\right)}
$$

where this formula determines a $P$-percent threshold confidence interval using the number of independent data segments/blocks, $n_{s}$, used in the Welch's periodogram method spectral estimator (see Miles ${ }^{12,13}$ ). The 95 percent confidence interval based on $n_{s}=128$ independent samples is 0.0233. However, the spectra are calculated using a 50 percent overlap to reduce the variance and the 95 percent threshold confidence interval based on $n_{s}=273$ samples is 0.0109. This horizontal line is also shown in Fig. 3(b). These indicators show the MSC function is reliable up to about $400 \mathrm{~Hz}$. However, as shown in Fig. 3(a) the MSC function is above 0.4 only in a region below $100 \mathrm{~Hz}$.

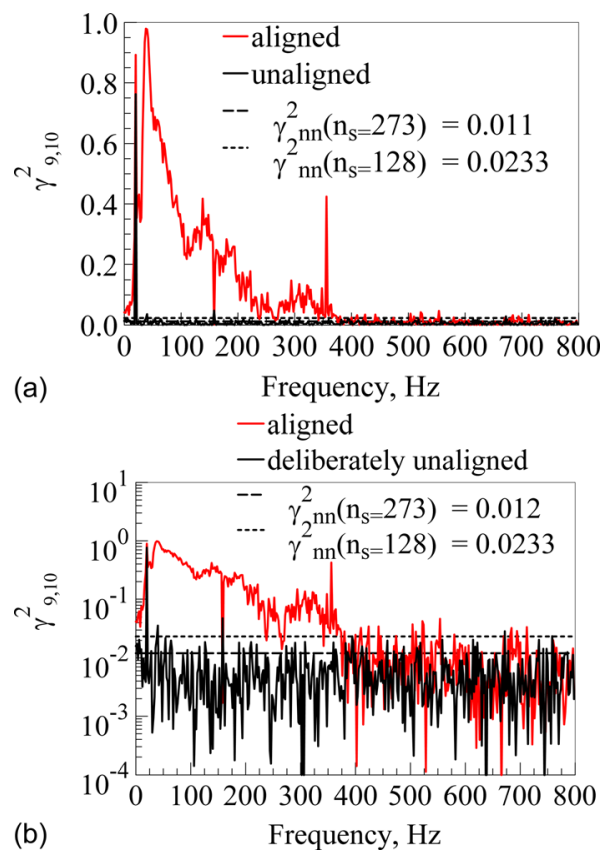

FIG. 3. (Color online) Coherence using sensors CIP1(9) and T551(10) at 48 percent maximum power (flight idle). (a) Linear scale, (b) logarithmic scale.
Miles ${ }^{12,13}$ shows that instead of relying on the confidence interval given by Eq. (2), which is based on a statistical theory, to obtain a threshold value for $\hat{\gamma}_{n n}^{2}\left(n_{s}\right)$, one can use a deliberately unaligned time history to create the threshold value. If one of the time histories is shifted by a time delay more than the segment/block length, $T_{d}=N / r_{s}$, then the two time histories are totally independent unless tones are present. This deliberate decorrelation establishes a coherence threshold and also identifies any tones in the signals. Shifting the signals by this time delay removes the coherence of random noise but leaves the coherence of periodic functions which are sometimes identified as hidden periodicities, concealed spectral lines, or undamped sinusoids in noise. The deliberately unaligned coherence is also shown in Fig. 3(b). Note that the higher statistical confidence interval based on the number of independent records $\left(n_{d}=128\right)$ is a more conservative estimate of the measured coherence threshold for the Honeywell TECH977 turbofan engine. Miles ${ }^{13}$ previously found that with a 50 percent overlap the higher statistical confidence interval based on the number of independent records is a more conservative estimate of the measured coherence threshold for measurements made in the Pratt \& Whitney PW4098 turbofan engine. Miles ${ }^{13}$ showed that for a Gaussian distribution and using a 50 percent overlap to reduce the variance, a coherence threshold calculated with $n_{o}=2 n s$ did work well. Consequently, simulations of internal turbofan engine noise with the assumption that it has a Gaussian distribution could lead to incorrect conclusions. The statistical coherence threshold can be used with confidence since it can be compared with a measured coherence threshold. The coherence value is below the 95 percent statistical confidence interval above $400 \mathrm{~Hz}$. Consequently, this is the upper frequency limit for which data are available for analysis using a linear system model. The linear system theory will be discussed next. Then, the enclosed ambient sound field theory will be developed using an approximate analytical formulation.

\section{UNENCLOSED LINEAR SYSTEM THEORY}

The methods used herein are based on system theory developed for linear systems with random inputs as discussed by Bendat and Piersol. ${ }^{24}$ In this paper, the linear system theory discussed is in the frequency domain. The output spectral density function, $\hat{G}_{y, y}$, and the cross-spectra density function, $\hat{G}_{x, y}$, is related to an input spectral density function, $\hat{G}_{x, x}$, through frequency response function, $H_{x, y}(f)$, representing the turbine as

$$
\hat{G}_{y, y}=\left|H_{x, y}(f)\right|^{2} \hat{G}_{x, x}
$$

and

$$
\hat{G}_{x, y}=H_{x, y}(f) \hat{G}_{x, x}
$$

where $x$ is the input signal from the combustor pressure sensor CIP1 and $y$ is the output signal from one of the turbine exit pressure sensors.

The cross-spectral density and the frequency response functions are complex valued quantities, which can be expressed in 
terms of a magnitude and an associated phase angle. This will be expressed herein using complex polar notation.

$$
\begin{aligned}
& \hat{G}_{x, y}(f)=\left|\hat{G}_{x, y}(f)\right| \exp [-j \hat{\phi}(f)], \\
& H_{x, y}(f)=\left|H_{x, y}(f)\right| \exp [-j \psi(f)] .
\end{aligned}
$$

Before plotting the cross-spectral density phase angle, phase unwrapping is applied to the phase angle to avoid a jump of $2 \pi$ in the phase caused by the ATAN 2 function. ${ }^{37}$

The system under consideration has a combustion noise input with a measured spectrum, $\hat{G}_{9,9}^{m}(f)$, which includes acoustic and hydrodynamic components. The system measured output quantities are assumed to be related as follows:

$$
\begin{aligned}
& \hat{G}_{9,10}^{m}(f)=H_{9,10}^{m}(f) \hat{G}_{9,9}^{m}(f), \\
& \hat{G}_{10,10}^{m}(f)=\left|H_{9,10}^{m}(f)\right|^{2} \hat{G}_{9,9}^{m}(f),
\end{aligned}
$$

and the measured MSC

$$
\hat{\gamma}_{9,10}^{2}=\frac{\left|\hat{G}_{9,10}^{m}\right|^{2}}{\hat{G}_{9,9}^{m} \hat{G}_{10,10}^{m}},
$$

where $m$ indicates noise may be included in the measured quantities. Only measurements with the combustor sensor, CIP1(9) and turbine exit sensor, T551(10), are discussed herein. The unknown that will be identified is the turbine frequency response function, $H_{9,10}^{m}(f)$ at a range of operating conditions.

\section{MODEL EQUATIONS}

The plant being modeled is the turbine and the sensor spatial correlation in the ambient noise field in the turbofan engine core. The input to the plant is the total pressure signal and the measurement made in the combustor is of the total pressure signal. Consequently, the available input autospectrum is that of the total pressure signal. A five parameter model is used for the transfer function. However, an eight parameter model is used for the enclosure sound field. Model parameters are adjusted so that agreement will be reached with the aligned measured cross-spectrum between the combustor and a turbine exit pressure sensor over the frequency range from $0-400 \mathrm{~Hz}$ and with the measured auto-spectra at the turbine exit sensor where the coherence is greater than 0.4 from $25-100 \mathrm{~Hz}$. In the region from $25-100 \mathrm{~Hz}$ the hydrodynamic noise is reduced and the turbine exit spectrum is not obscured by hydrodynamic noise. However, in this region it is obscured by the enclosure sound field. Normally, one might just fit the cross-spectra and compare the predicted and measured auto-spectra at the turbine exit. However, the enclosure sound field shows up in the turbine exit auto spectra in the $25-100 \mathrm{~Hz}$ range so that region is used in the curve fit.

Next, the measured auto-spectra at the turbine exit and the estimated auto-spectra at the turbine exit will be compared and adjustments are made to the enclosure sound field model until a satisfactory result is obtained. The general idea is to show that the data indicate the transfer function interpretation is reasonable if the enclosure sound field is taken into account. To aid in physical interpretation, a standard template parametric model form will be used. The model form examined in this paper is in a parametric reduced order frequency domain representation. The parameters depend nonlinearly on the operating point. However, at each operating condition the system will be assumed to be linear and the same parametric form will be used so that source separation will be obvious. The nonlinear operation is then described by a linear model at a range of observed operating points each identified by a set of parameters. This paper discusses measurements at the $48,54,60,71,87$ percent maximum power settings and at a maximum power setting. The transfer function of the turbine is modeled using the simplest possible dynamic system which is one which satisfies a first order, linear differential equation with a time delay for the indirect combustion noise, and no time delay for the direct combustion noise. Systems with time delays are in a class of systems discussed in books on linear time invariant system theory such as the text by Schetzen. ${ }^{38}$

The objective in this section is to separate the combustion noise at the turbine exit from broadband noise from other sources and hydrodynamic pressure perturbations. The frequency region from about $0-50 \mathrm{~Hz}$ is a region where the measurements are masked by the ambient enclosure sound field which can be determined since the transducers are situated within an acoustic wavelength of one another. An additional ambient enclosure noise field model based on diffuse noise field theory is needed to match the measurements, and it will be discussed after the linear system theory sections.

In this model any upstream propagating indirect combustion noise and any direct combustion noise reflected upstream from the turbine entrance are included in the combustion auto spectrum $G_{x, x}(f)$.

Consider an input signal $x(t)$ with a spectrum $G_{x, x}(f)$ for a system with transfer function $H_{x, y}(f)$ and output signal $y(t)$. Now that the statistical nature of the calculations is established, the notation is dropped for simplicity. Then the crossspectrum is given by Eq. (4). For the turbofan engine, the input to the turbine is the direct acoustic signal, $x_{d}(t)$, and the time delayed entropy signal, $x_{i}(t)$, with a post-combustion residence time delay in the combustor of $\tau_{p c}$. The time delayed signal may represent in addition to a temperature fluctuation moving with the flow any other disturbance moving with the flow such as a density or vorticity fluctuation. A turbine-combustortailpipe noise system diagram is shown in Fig. 4. Note the presence of a combustor entropy noise, $N_{i}$, combustor hydrodynamic noise, $N_{d}$, and turbine exit tailpipe noise, $N_{T}$.

The system model is constructed as follows. The output turbine noise signals are the direct and indirect combustion noise $y_{d}(t)$ and $y_{i}(t)$ as shown in Fig. 4. The output signal measured at the turbine exit, $y$, is the sum of the direct combustion noise signal, $y_{d}$, and the indirect combustion noise signal, $y_{i}$,

$$
y=y_{i}+y_{d}
$$

The direct combustion noise cross-spectral density, $G_{x_{d} y_{d}}$, is a product of the direct combustion noise turbine transfer 


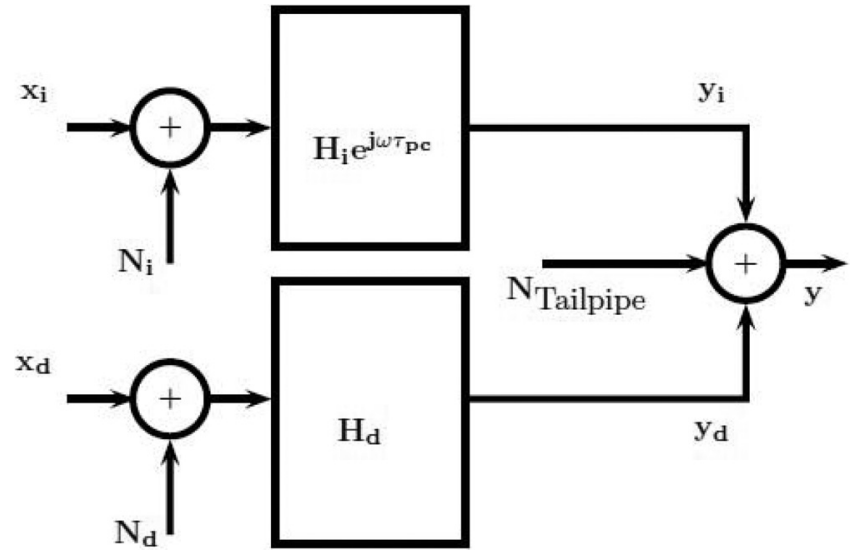

FIG. 4. Turbine-combustor-tailpipe noise system.

function, $H_{d}(f)$, and the direct combustion noise input spectral density, $G_{x_{d}}$, and an acoustic travel time delay function which is included for completeness

$$
G_{x_{d} y_{d}}=H_{d}(f) e^{j 2 \pi f \tau_{\mathrm{A}}} G_{x_{d}} .
$$

When discussing auto spectra, the notation used is sometimes simplified so that we write $G_{x_{d}}$ for $G_{x_{d} x_{d}}$.

The indirect combustion noise cross-spectral density, $G_{x_{d} y_{i}}$, is a product of the indirect combustion noise turbine transfer function, $H_{i}(f)$, the time delay factor, $e^{j \varphi}$, and the input indirect combustion noise spectral density, $G_{x_{i}}$, which corresponds to an equivalent fluctuating entropy spectral density function.

$$
G_{x_{d} y_{i}}=H_{i}(f) e^{j \varphi} G_{x_{i}}
$$

where $\varphi=\left(2 \pi f \tau_{p c}+\varphi_{o} \pi / 180\right) 180 / \pi$ is measured in degrees and $\tau_{p c}$ is the post-combustion residence time in the combustor. The pressure sensors are not phase matched and the phase angle $\varphi_{o}$ accounts for this. The two turbine exit sensors are assumed to be phase matched.

The direct combustion noise and the entropy noise have the same origin in the combustion process. Consequently, it is assumed that at the turbine exit the resulting spectrum from the input entropy fluctuation spectral density can be modeled by an equivalent input acoustic spectral density and a transfer function

$$
H_{i}(f) e^{j \varphi} G_{x_{i}}=H(f) e^{j \varphi} G_{x_{d}} .
$$

This assumption is possible since the post-combustion time delay is observable in the cross-spectrum between the combustor and the turbine exit. Consequently, the observed indirect combustion noise and the direct combustion noise are coherent.

The direct combustion noise turbine transfer function $H_{d}(f)$ in Eq. (11) is assumed to have a representation $\nu H(f)$. Where $\nu$ is a measure of the ratio of the direct combustion noise to the indirect combustion noise,

$$
H_{d}(f)=\nu H(f)
$$

Consequently, using Eqs. (13) and (14), the measured crossspectral density at the turbine exit is given by

$$
\begin{aligned}
G_{x_{d}, y} & =G_{x_{d} y_{d}}+G_{x_{d} y_{i}}=H_{d}(f) e^{j 2 \pi f \tau_{A}} G_{x_{d}}+H_{i}(f) e^{j \varphi} G_{x_{i}} \\
& =H(f)\left(e^{j \varphi}+\nu e^{j 2 \pi f \tau_{A}}\right) G_{x_{d}} .
\end{aligned}
$$

In order to create a more desirable cross-spectrum phase angle variation with frequency so the enclosed sound field can be studied, a time delay $\tau_{o}$ is removed by properly aligning the time histories by $3.05 \mathrm{~ms}$ or 200 time steps $(3.05176=200 * 1000 /$ $65536)$. The resulting cross-spectrum phase angle variation with frequency permits the determination of the sensor pair spatial correlation function with greater accuracy.

The alignment time delay, $\tau_{o}$, is known. This time delay is removed by a signal processing alignment procedure leaving the aligned cross-spectral density, $U_{x_{d}, y}$, where

$$
\begin{aligned}
U_{x_{d}, y} & =e^{-j 2 \pi f \tau_{o}} G_{x_{d}, y} \\
& =H(f)\left(e^{j\left(\varphi-2 \pi f \tau_{o}\right)}+\nu e^{j 2 \pi f\left(\tau_{A}-\tau_{o}\right)} G_{x_{d}} .\right.
\end{aligned}
$$

The combustor entropy noise, $N_{i}$, and combustor hydrodynamic noise, $N_{d}$, are assumed to be independent of each other and independent of the tailpipe noise, $N_{T}$.

$$
G_{N_{i} N_{d}}=G_{N_{i} N_{T}}=G_{N_{d} N_{T}}=0 .
$$

The frequency response function of the turbine is modeled using the simplest possible dynamic system which is one which satisfies a first order, linear differential equation

$$
H(f)=\frac{K}{1+j 2 \pi f \tau_{T}}
$$

where $K$ will be used to measure the indirect combustion noise created as a fraction of the noise in the combustor.

This approach requires the input signal which is the measured combustor acoustic auto-spectrum, $\hat{G}_{9,9}^{m}$, be free of noise. However, the input signal is contaminated by hydrodynamic noise and higher acoustic modes that are cutoff in the turbine. In addition, indirect combustion noise propagating upstream and direct combustion noise reflected from the turbine entrance may be present. The presence of noise limits the frequency range of the measured cross spectrum, $\hat{G}_{9,10}^{m}$ to $400 \mathrm{~Hz}$ because the cross-spectrum is not as affected by noise as long as the coherence is above the coherence threshold which is reached near $400 \mathrm{~Hz}$ as shown in Fig. 3. The frequency range of the measured turbine exit auto-spectrum, $\hat{G}_{10,10}^{m}$, unaffected by noise is limited to $100 \mathrm{~Hz}$ based on the coherence function shown in Fig. 3 because the coherence falls below 0.4 at frequencies above $100 \mathrm{~Hz}$.

Since a frame of reference adjustment has been made using the alignment time delay, $\tau_{o}$, the estimated form of the free field system transfer function, $H_{9,10}^{\mathrm{E}}(f)$, is

$$
\mathcal{H}_{9,10}^{\mathrm{E}}=\frac{\left(e^{j\left(\varphi-2 \pi f \tau_{o}\right)}+\nu e^{j 2 \pi f\left(\tau_{A}-\tau_{o}\right)}\right)}{1+j 2 \pi f \tau_{T}},
$$




$$
H_{9,10}^{\mathrm{E}}(f)=K \mathcal{H}_{9,10}^{\mathrm{E}},
$$

where $K$ is the coherent indirect combustion noise turbine transmission creation factor and $K \nu$ is the coherent direct combustion noise turbine transmission loss factor.

The unenclosed transfer function factor $\mathcal{H}_{9,10}^{\mathrm{E}}$ will be used in the section discussing the enclosed transfer function. Consequently, it has a separate terminology. In the next section, the unenclosed transfer function $H_{9,10}^{\mathrm{E}}(f)$ is discussed to specify relate the measured cross-spectra and auto-spectra to the proposed model if no enclosure was present.

\section{UNENCLOSED SOUND FIELD}

If free field data were available because the enclose was absent only a six parameter model would be used for the estimated transfer function to fit measured values of $\left|\hat{U}_{9,10}^{m}\right|$, $\hat{\phi}_{9,10}^{m \text {, aligned }}$, and $\hat{G}_{10,10}^{m}$. This would be done using estimated values as follows:

$$
\begin{aligned}
& 10 \log \left(\left|U_{9,10}^{\mathrm{E}}\right|\right)= 10 \log \left(\left|\frac{\left(e^{j\left(\varphi-2 \pi f \tau_{o}\right)}+\nu e^{-j 2 \pi f\left(\tau_{A}-\tau_{o}\right)}\right)}{1+j 2 \pi f \tau_{T}}\right|\right) \\
&+10 \log (K)+10 \log \left(\hat{G}_{9,9}^{m}\right), \\
& \phi_{9,10}^{E \text { aligned }}(f)=\tan ^{-1}\left\{\Im\left(H_{9,10}^{\mathrm{E}}(f)\right), \Re\left(H_{9,10}^{\mathrm{E}}(f)\right)\right\} 180 / \pi,
\end{aligned}
$$

$$
\begin{aligned}
10 \log \left(G_{10,10}^{\mathrm{E}}\right)= & 20 \log \left(\left|\frac{\left(e^{j\left(\varphi-2 \pi f \tau_{o}\right)}+\nu e^{-j 2 \pi f\left(\tau_{A}-\tau_{o}\right)}\right)}{1+j 2 \pi f \tau_{T}}\right|\right) \\
& +20 \log (K)+10 \log \left(\hat{G}_{9,9}^{m}\right)
\end{aligned}
$$

where $\left|U_{9,10}^{\mathrm{E}}\right|$ is the estimated free field combustor/turbine exit pressure cross-spectrum magnitude, $\phi_{9,10}^{\text {Ealigned }}$ is the estimated free field combustor/turbine exit pressure crossspectrum phase angle, and $G_{10,10}^{\mathrm{E}}$ is the estimated free field turbine exit pressure auto spectrum. The six parameters are $K$, $\nu, \tau_{T}, \tau_{p c}, \tau_{A}$, and $\varphi_{o}$. If the turbine exit noise is from the direct combustion noise source, $\nu K$ is the turbine noise attenuation factor. However, if the turbine exit noise is from the indirect combustion noise source, $K$ is an indirect combustion noise production/creation factor. The value of $\nu$ indicates the contribution of direct combustion noise. The value of $\tau_{T}$ in addition to changing the phase angle also adjusts the slope of the magnitude of the estimated cross-spectral density function, $\left|U_{9,10}^{\mathrm{E}}\right|$.

The value of $\tau_{A}$ is much smaller than the value of $\tau_{o}$ since the speed of sound in the combustor greatly exceeds the flow velocity. Consequently, $\tau_{A}$ will be neglected and only five parameters define the free field (missing enclosure) system. However, the measurements are masked by the ambient enclosed sound field in the low frequency range which can be determined because the transducers are situated within an acoustic wavelength of one another in a closed space. The next section discusses the sensor pair spatial correlation model for ambient enclosed core noise.

\section{SPATIAL CORRELATION COEFFICIENTS FOR AMBIENT CORE NOISE}

The enclosed space is shown in the cutaway engine diagram shown in Fig. 1. The dimensions are proprietary. Three elementary spatial correlation coefficients for ambient enclosed noise fields are discussed by Cook et al. ${ }^{20}$ and Nélisse and Nicolas. ${ }^{26}$ They are derived as follows by Cook et $a l .{ }^{20}$ except that in this derivation the assumption is made that at $f=0$ the sensors are not in phase. The spatial correlation between the sound pressures at two sensors $A$ and $B$ separated by a distance $r_{m}$ in a sound field is

$$
R=\frac{\left\langle p_{1} p_{2}\right\rangle}{\sqrt{\left(\left\langle p_{1}^{2}\right\rangle\left\langle p_{2}^{2}\right\rangle\right)}}
$$

where $p_{1}$ and $p_{2}$ are the pressures at points $A$ and $B$, respectively, and the angular brackets denote long time averages.

If $p_{1}$ and $p_{2}$ are both sinusoidal of the same frequency, but differ in phase by $\beta$, then $R=\cos (\beta)$ where $p_{1}=A \cos (\omega t)$ and $p_{2}=B \cos (\omega t-\beta)$ since

$$
R=\Re\left(\frac{A e^{j \omega t} B e^{-j(\omega t-\beta)}}{\sqrt{A^{2} B^{2}}}\right)=\Re\left(e^{j \beta}\right)=\cos (\beta) .
$$

Suppose a plane wave of wavelength $\lambda$ passes over the points $A$ and $B$ with $\psi$ being the angle between the normal to the wave fronts and the line $A B$. The phase difference between the two points is $\beta=\frac{2 \pi r_{m} \cos (\psi)}{\lambda}$. Consequently, the two points are in phase, i.e., $\beta=2 \pi$ if $r_{m}=\lambda$ and $\psi=0^{\circ}$ and out of phase if $\psi=90^{\circ}$. Then the one dimensional ambient sound field spatial correlation for in phase sensors is $R=\cos (\beta)=\cos \left(k r_{m} \cos (\psi)\right)$. However, the sensors used herein are not necessarily in phase at $f=0$, so the one dimensional ambient core noise sound field spatial correlation used is $R_{1}=\cos (\beta)$ $=\cos \left(k r_{m} \cos (\psi)-\vartheta_{o}\right)$.

If the sound field is random in two dimensions so that the normals to the wave fronts all lie in the same plane and all directions have equal weights, then the two dimensional ambient sound field spatial correlation is

$$
R_{2}=\frac{1}{2 \pi} \int_{0}^{2 \pi} \cos \left(k r_{m} \cos (\psi)-\vartheta_{o}\right) d \psi=\cos \left(\vartheta_{o}\right) J_{0}\left(k r_{m}\right),
$$

where $J_{0}$ the Bessel function of zero order.

If the sound field is random in three dimensions and all directions have equal weights, then the three dimensional isotropic ambient sound field spatial correlation is

$$
\begin{aligned}
R_{3} & =\frac{1}{4 \pi} \int_{0}^{\pi} d \phi \int_{0}^{2 \pi} \cos \left(k r_{m} \cos (\psi)-\vartheta_{o}\right) \sin (\psi) d \psi \\
& =\cos \left(\vartheta_{0}\right) \frac{\sin \left(k r_{m}\right)}{k r_{m}} .
\end{aligned}
$$

The isotropic spatial correlation coefficient is used to evaluate the diffuse sound field in diverse spaces and reverberant spaces 
such as rooms by Cook et al. ${ }^{20}$ and Néllisse and Nicolas, ${ }^{26}$ and wind tunnels by Piersol ${ }^{23,25}$ and Bendat and Piersol. ${ }^{24}$

In an isotropic noise field the directional density of the noise is uniform so that the same amount of noise arrives from all directions. The core noise ambient field spatial correlation model will be constructed using a nonisotropic two dimensional noise field spatial correlation function. In addition, an anisotropic one dimensional noise field will be used. This is similar to the use of an isotropic three dimensional noise field and an anisotropic surface noise source field in the study of ambient sea noise by Cron and Sherman. ${ }^{21}$

The models will be specified by an a ambient core noise travel time $\tau$ using the relationships

$$
\begin{aligned}
& \tau=\frac{r_{m}}{c}, \\
& c=\lambda f, \\
& k r_{m}=\frac{2 \pi r_{m}}{\lambda}=\frac{2 \pi f r_{m}}{c}=2 \pi f \tau,
\end{aligned}
$$

since while distances and velocities are unknown, the frequency is known and the appropriate time constant $\tau$ can be estimated from the data. This approach avoids limitations imposed by the lack of proprietary geometry and flow information.

In this paper, we define a one dimensional anisotropic core spatial correlation function where we assume the normal of the wave fronts is parallel to the line between the sensors and consequently $\psi=0$. Three parameters are used since the sensors may not be in phase. Two of these spatial correlation functions are used herein

$$
\begin{aligned}
& \zeta_{1}(f)=\alpha_{c 1} \cos \left(2 \pi f \tau_{c 1}-\vartheta_{c 1}\right), \\
& \zeta_{2}(f)=\alpha_{c 2} \cos \left(2 \pi f \tau_{c 2}-\vartheta_{c 2}\right),
\end{aligned}
$$

and a two dimensional ambient turbine exit spatial correlation function where we use two parameters

$$
\eta(f)=\alpha_{T E} J_{0}\left(2 \pi f \tau_{T E}\right) .
$$

The total spatial correlation, $\rho(f)$ is

$$
\rho(f)=\eta(f)+\zeta_{1}(f)+\zeta_{2}(f) .
$$

\section{ENCLOSED SOUND FIELD}

This model is designed to fit the large scale structure in the interference pattern in the phase angle due to the entropy waves which have longer time delays.

We then have for the ambient acoustic closed space core noise transfer function, cross-spectrum, and turbine exit auto-spectrum, which are compared to the measurements

$$
\begin{aligned}
& \mathcal{H}_{9,10}^{\mathrm{A}}=\mathcal{H}_{9,10}^{\mathrm{E}}+\zeta_{1}(f)+\zeta_{2}(f)+\eta(f), \\
& 10 \log \left(\left|U_{9,10}^{\mathrm{A}}\right|\right)= 10 \log \left(\mathcal{H}_{9,10}^{\mathrm{A}}\right) \\
&+10 \log (K)+10 \log \left(\hat{G}_{9,9}^{m}\right),
\end{aligned}
$$

$$
\begin{aligned}
& \phi_{9,10}^{\text {A aligned }}(f)=\tan ^{-1}\left\{\Im\left(\mathcal{H}_{9,10}^{\mathrm{A}}(f)\right), \Re\left(\mathcal{H}_{9,10}^{\mathrm{A}}(f)\right)\right\} 180 / \pi \\
& 10 \log \left(G_{10,10}^{\mathrm{A}}\right)= 20 \log \left(\left|\mathcal{H}_{9,10}^{\mathrm{A}}\right|\right)+20 \log (K) \\
&+10 \log \left(\hat{G}_{9,9}^{m}\right)
\end{aligned}
$$

where the enclosure sound field is a fraction of the combustion sound field, $\hat{G}_{9,9}^{m}$, and $K$ is an appropriate attenuation factor.

\section{PARAMETER EVALUATION PROCEDURE}

Model parameters were first selected and adjusted so that the auto-spectra and cross-spectra created by the system model were in fair agreement with the measured values. Next, an appropriate cost function is used to fine tune these model parameters. The cost function is outlined in the Appendix. The cost function uses factors to place more weight on the least square error values which are considered more reliable. A higher reliability is placed on the measured phase angle from $0-250 \mathrm{~Hz}$, the measured cross-spectrum magnitude, and the turbine exit auto-spectrum from 0-100 $\mathrm{Hz}$ than the measured phase angle from $252-400 \mathrm{~Hz}$. A solution method that provides an optimum solution in a least squares sense without derivatives is used. The search technique used in this study is described by Powell ${ }^{39}$ and a FORTRAN computer code for this algorithm is given by Shapiro and Goldstein, ${ }^{40}$ and Kuester and Mize. ${ }^{41}$ The model parameters determined for the $48,54,60,71,87$ percent of maximum power operating condition cases and one maximum power case are shown in Table II, and selected parameters are shown in Fig. 5. The exact power setting of the maximum power case is unknown. To make it possible to plot the maximum power parameters, the maximum power case is arbitrarily assigned a value of 99 percent of maximum power.

Figure 5 shows parameters related to the turbine and flow system. Figure 5(a) shows the ratio of direct to indirect coherent combustion noise $\nu$ is about 26 percent at the lowest power setting and then drops from 12 percent at 50 percent of maximum power to 5 percent at the maximum power setting. Figure 5(b) shows the post-combustion residence time in the combustor $\tau_{p c}$ ranges from about $3.4 \mathrm{~ms}$ at low engine speed to about $2.9 \mathrm{~ms}$ at the maximum power setting.

Examining Table II shows the turbine acoustic attenuation/creation level, $10 \log (K)$, ranges from -5 to $-9 \mathrm{~dB}$. This means the loss/production of acoustic power across the turbine that can be attributed to the transfer function ranges from $10 \mathrm{~dB}$ to $18 \mathrm{~dB}$. The level of the coherent noise at the turbine exit attributed to the transfer function is $10 \mathrm{~dB}$ to 18 $\mathrm{dB}$ below the level of the combustion noise. An additional loss is apparent which is attributed to phase cancelation due to the spatial correlation in the ambient core noise field. This can be more than $6 \mathrm{~dB}$.

Examining Table II shows the system behaves like a first order linear system with a time constant, $\tau_{T}$, ranging 
TABLE II. Model parameters.

\begin{tabular}{|c|c|c|c|c|c|c|}
\hline $\begin{array}{l}\text { Parameter } \\
\text { Percent maximum }\end{array}$ & $\begin{array}{c}\text { Value } \\
48\end{array}$ & 54 & 60 & 71 & 87 & 99 \\
\hline$\nu\left(\epsilon_{1}\right)$ & 0.2585567 & 0.09519884 & 0.1227427 & 0.08256044 & 0.08220044 & 0.05111235 \\
\hline $10 \log (K)\left(\epsilon_{2}\right)$ & -8.38677 & -5.007134 & -7.788622 & -9.343841 & -7.906158 & -7.422281 \\
\hline$\tau_{T}\left(\epsilon_{3}\right), \mathrm{s}$ & 0.001595392 & 0.0006247073 & 0.001532724 & 0.001444117 & -0.0009414114 & $-3.963765 \mathrm{e}-09$ \\
\hline$\tau_{p c}\left(\epsilon_{4}\right), \mathrm{ms}$ & 3.437903 & 3.446463 & 3.293785 & 3.047519 & 3.172503 & 2.940178 \\
\hline$\varphi_{o}\left(\epsilon_{5}\right), \operatorname{deg}$ & 0.2492384 & -2.887404 & -1.424596 & -6.793756 & -4.927228 & -18.28111 \\
\hline$\alpha_{T E}\left(\epsilon_{6}\right)$ & -0.9847035 & -0.3625233 & -0.5555566 & -0.2957081 & -0.5565302 & -0.6333497 \\
\hline$\tau_{T E}\left(\epsilon_{7}\right), \mathrm{ms}$ & 7.659317 & 7.83757 & 7.748561 & 7.443147 & 7.839088 & 8.172998 \\
\hline$\alpha_{c 1}\left(\epsilon_{8}\right)$ & -0.2224676 & -0.5898645 & -0.3994165 & -0.3836406 & -0.4160725 & -0.3804713 \\
\hline$\tau_{c 1}\left(\epsilon_{9}\right), \mathrm{ms}$ & 6.013163 & 2.565741 & 3.541956 & 2.361771 & 3.108431 & 3.203457 \\
\hline$\vartheta_{c_{1}}\left(\epsilon_{10}\right), \operatorname{deg}$ & 89.12107 & -0.2313568 & 29.9959 & 360.0005 & 61.16767 & 90.33118 \\
\hline$\alpha_{c 2}\left(\epsilon_{11}\right)$ & -0.3837000 & -0.9980998 & -0.3701099 & -1.999444 & -0.4794316 & -0.8302187 \\
\hline$\tau_{c 2}\left(\epsilon_{12}\right), \mathrm{ms}$ & 3.986773 & 1.334677 & 2.658769 & 0.1102978 & 1.634171 & 1.037572 \\
\hline$\vartheta_{c_{2}}$, deg & 90.68719 & 88.36214 & 90.15674 & 274.7305 & 90.09822 & 86.5299 \\
\hline
\end{tabular}

from 0 to $1.5 \mathrm{~ms}$. The time constants for the one dimensional ambient core noise spatial correlation functions, $\zeta_{1}(f)$ and $\zeta_{2}(f)$, which are $\tau_{c_{1}}$ and $\tau_{c_{2}}$, and the two dimensional ambient core noise spatial correlation function, $\eta(f)$, which is $\tau_{T E}$ are shown in Table II. At low power settings the three dimensional ambient core noise spatial correlation function time constant $\tau_{T E}$ is about $8 \mathrm{~ms}$. At low power settings the one dimensional ambient core noise spatial correlation function time constant $\tau_{c_{1}}$ and $\tau_{c_{2}}$ ranges from $0.1-6 \mathrm{~ms}$.

\section{RESULTS}

Results for the 48, 54, 71, and 87 percent maximum power case are shown in Figs. 6-9. Two figures are used to compare the estimated acoustic cross-spectrum magnitude and phase with measured values over the frequency range from $0-400 \mathrm{~Hz}$. These figures also show the combustion
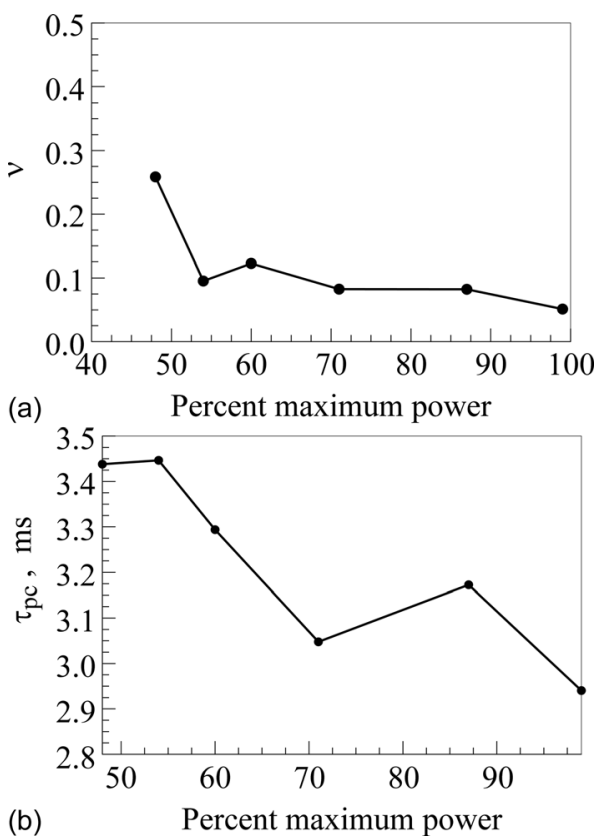

FIG. 5. Turbine/flow system parameters as a function of percent maximum power. (a) Ratio of direct to indirect combustion noise, (b) post-combustion residence time in combustor. region auto-spectra and the measured and estimated turbine exit auto-spectra.

The large scale variation of the cross-spectrum phase angle with frequency is captured by the ambient core noise spatial coherence function used herein as shown in (a) of Figs. 6-9.

The estimated and measured cross-spectrum magnitude and phase angle shown in Figs. 6-9 are in good agreement from $0-400 \mathrm{~Hz}$. The estimated and measured turbine exit auto-spectrum shown in (b) of Figs. 6-9 are in fair agreement from $0-100 \mathrm{~Hz}$ in these figures. Above $100 \mathrm{~Hz}$, the auto-spectra results at the turbine exit are obscured by hydrodynamic and uncorrelated acoustic noise.

The spatial correlation function, $\rho(f)$, and its components $\left[\eta(f), \zeta_{1}(f), \zeta_{2}(f)\right]$ which are used to model the data for each case are shown in Figs. 10 and 11. For clarity, since at
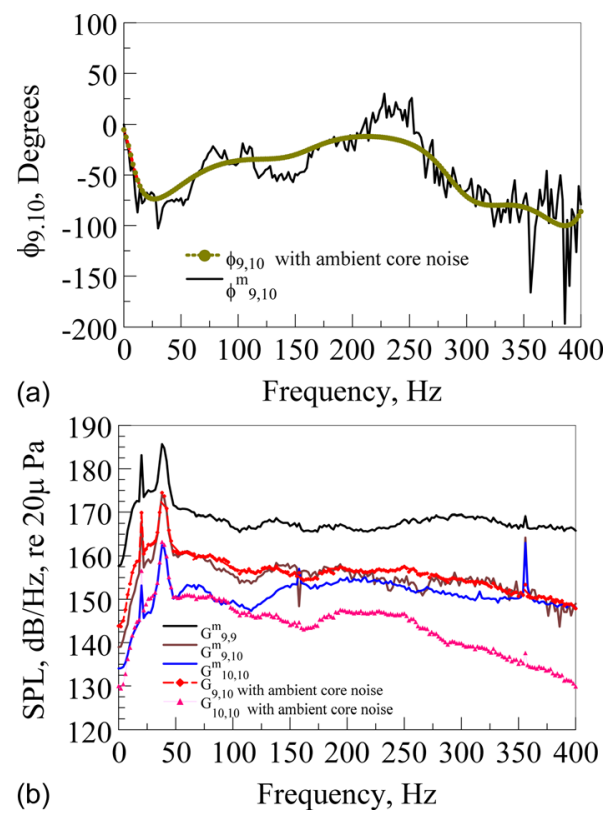

FIG. 6. (Color online) Cross-spectrum turbofan engine at 48 percent maximum power (flight idle) using sensors CIP1(9) and T551(10) from 0-400 Hz. Phase angle shown using alignment of 200 counts or $3.05 \mathrm{~ms}$. (a) Phase angle, (b) magnitude. 

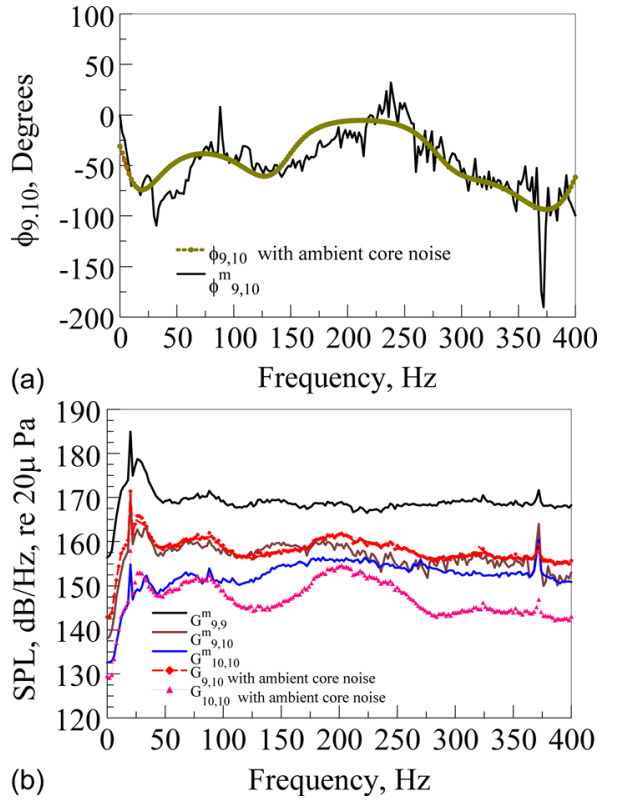

FIG. 7. (Color online) Cross-spectrum turbofan engine at 54 percent maximum power (approach) using sensors CIP1(9) and T551(10) from 0-200 $\mathrm{Hz}$. Phase angle shown using alignment of 200 counts or $3.05 \mathrm{~ms}$. (a) Phase angle, (b) magnitude.

$f=0$, the components and the spatial correlation function are negative, each item has been multiplied by -1 before plotting. The observed $9 \mathrm{~dB}$ to $10 \mathrm{~dB}$ attenuation of the combustion noise shown in plots of the cross-spectrum magnitude in Figs. 6(b)-9(b) is normally attributed to the turbine. Examination of Figs. 10 and 11 shows the actual turbine attenuation can be less by 2 to $6 \mathrm{~dB}$ or more at some frequencies. A good part of the attenuation measured may be due to destructive interference due to the spatial correlation in the enclosed core noise sound field of the turbofan engine. As a result, the
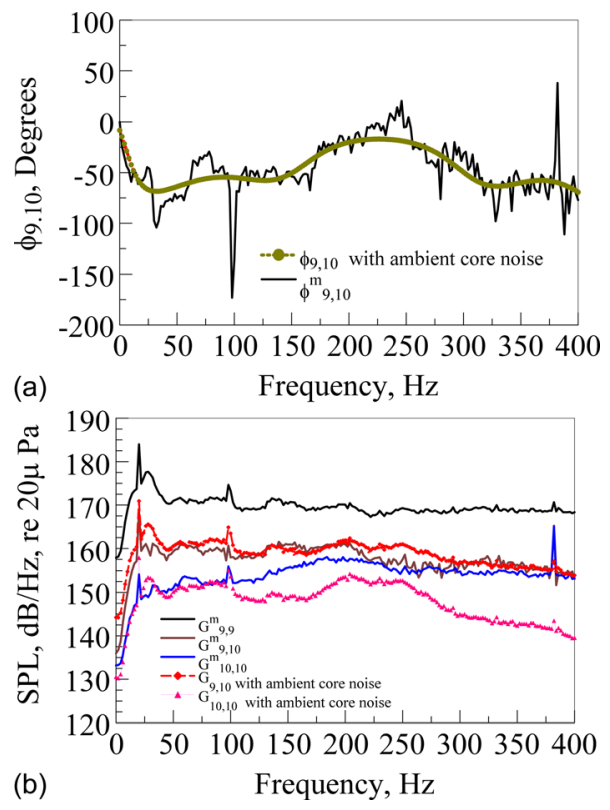

FIG. 8. (Color online) Cross-spectrum turbofan engine at 71 percent maximum power (cutback) using sensors CIP1(9) and T551(10) from 0-400 Hz. Phase angle shown using alignment of 200 counts or 3.05 ms. (a) Phase angle, (b) magnitude.
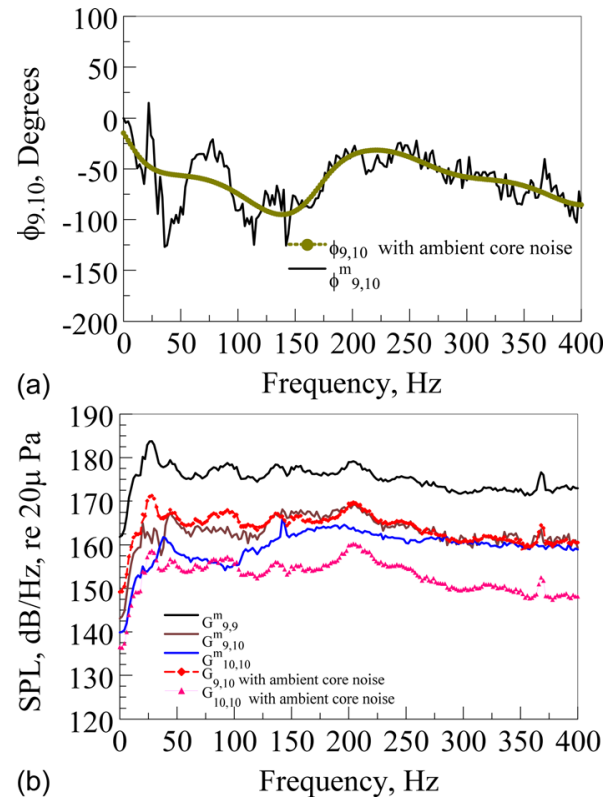

FIG. 9. (Color online) Cross-spectrum turbofan engine at 87 percent maximum power (takeoff) using sensors CIP1(9) and T551(10) from 0-400 Hz. Phase angle shown using alignment of 200 counts or $3.05 \mathrm{~ms}$. (a) Phase angle, (b) magnitude.

transfer function attenuation $10 \log (K)$ shown in Table II ranges from -5 to $-9 \mathrm{~dB}$.

The total cost function value, $C$, and the components $S_{1}$, $S_{1 a}, S_{2}$, and $S_{3}$ are defined in the Appendix and tabulated for each power setting in Table III. The components are least square fit values. The value of the least square fit error to the cross-spectrum phase angle from $0-250 \mathrm{~Hz}, S_{1}$, increases as the engine speed increases indicating the simple model used matches the measurements better at low engine speeds. This is also reflected in the total cost function $C$ also shown in

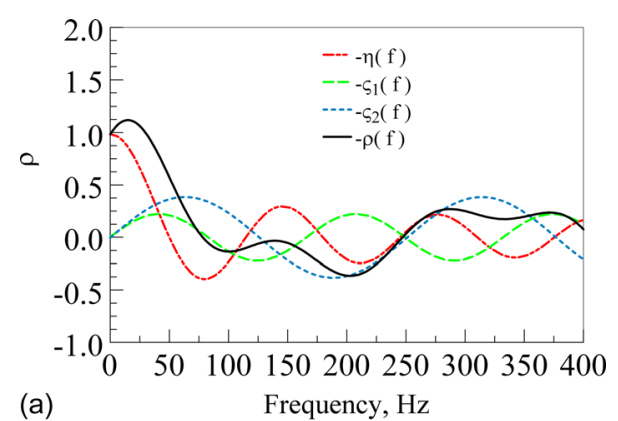

(a)

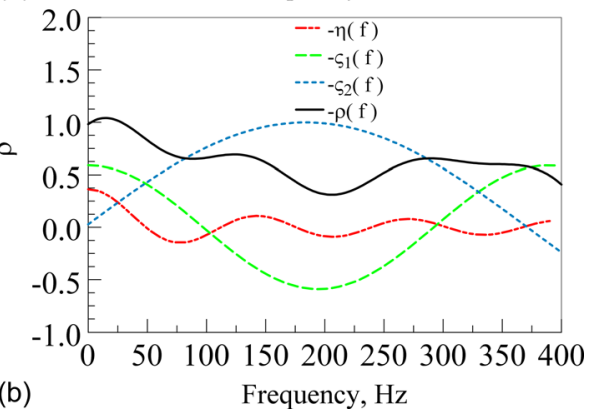

FIG. 10. (Color online) Spatial correlation function at 48 and 54 percent maximum power. (a) 48 percent maximum power (flight idle), (b) 54 percent maximum power (approach). 

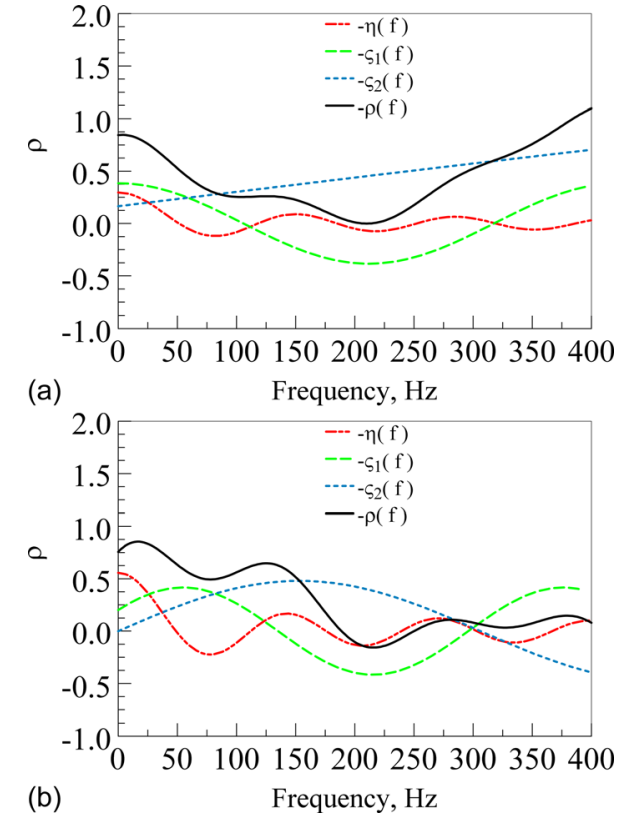

FIG. 11. (Color online) Spatial correlation function at 71 and 87 percent maximum power. (a) 71 percent maximum power (cutback), (b) 87 percent maximum power (takeoff).

Table III. The value of the least square fit error to the crossspectrum phase angle from $252-400 \mathrm{~Hz}, S_{1 a}$, decreases as the engine speed increases indicating the simple model used matches these measurements better at high engine speeds. The least square fit error to the cross-spectrum magnitude, $S_{2}$, does not vary much with engine speed. The least square fit error to the turbine exit auto spectrum, $S_{3}$, is larger at the higher engine speed.

\section{DISCUSSION}

\section{A. Estimated transfer function}

The most significant result is the good agreement between the aligned measured and estimated cross-spectra shown in Figs. 6-9. That this is achieved with only a five parameter curve fit using as a transfer function of the turbine the simplest possible dynamic system which is one which satisfies a first order, linear differential equation with a time delay for the indirect combustion noise and with no time delay for the direct combustion noise is remarkable. The linear system model produces good agreement between the measured and estimated cross-spectral density function from 0-400 Hz. In addition, the linear system model produces fair agreement between the measured and estimated turbine exit auto-spectral density function from $0-100 \mathrm{~Hz}$ where the system acoustic random noise is negligible.

At some frequency in the $100-400 \mathrm{~Hz}$ frequency range the measured turbine exit auto spectrum and the measured combustor/turbine exit cross-spectrum magnitude approach the same level and there is no way to make judgments about the transfer function approach to predict the turbine exit auto-spectrum. Hydrodynamic or uncorrelated noise makes it impossible to compare the estimated turbine exit autospectrum in the 100 to $400 \mathrm{~Hz}$ frequency range. However, the results suggest that indirect combustion noise is most important in the $0-100 \mathrm{~Hz}$ frequency range. The results show the importance of treating the turbofan noise source as a system rather than a collection of separate noise generating parts. The results provide insight into the part indirect combustion noise plays as a source low frequency core noise for this engine.

The observed attenuation of the combustion noise shown is normally attributed to the turbine. The actual turbine attenuation is less by 2 to $6 \mathrm{~dB}$ or more at some frequencies. A large part of the attenuation measured is from destructive interference due to the spatial correlation in the core noise sound field of the turbofan engine. This underlying physics is not included in current combustion noise prediction schemes. The current combustion noise prediction capability applies over a very narrow design space. Consequently, new turbofan engine core configurations might be outside the current combustion noise prediction capability.

\section{B. Spatial correlation, interference patterns, and nonlinearity}

The correlation structure of the enclosed ambient core noise shown in Figs. 10 and 11 differs from that of a diffuse sound field which might be found in measurements in reverberant rooms or wind tunnels. A diffuse sound field is one in which the time average of the mean-square sound pressure is the same everywhere and the flow of acoustic energy in all directions is equally probable. The model is anisotropic because the ambient core noise sound field is based on a two dimensional spatial correlation function and a one dimensional spatial correlation function with a sound field parallel to the microphone axis. An anisotropic formulation of spatial coherence is also used in the study of ocean noise spatial coherence. For example, the ambient noise field in the ocean is analyzed as a superposition of an anisotropic noise field due to the ocean surface in an isotropic noise field by Cron and

TABLE III. Cost function analysis, $C=\left(S_{1} * 1000+S_{1 a} * 200+S_{2} * 800+S_{3} * 1000\right) / 201$.

\begin{tabular}{|c|c|c|c|c|c|c|}
\hline $\begin{array}{l}\text { Cost } \\
\text { Percent maximum }\end{array}$ & $\begin{array}{l}\text { Value } \\
48\end{array}$ & 54 & 60 & 71 & 87 & 99 \\
\hline $\mathrm{C}$ & 0.6250858 & 0.5526794 & 0.6700567 & 0.8762981 & 1.01022 & 0.9716793 \\
\hline$S_{1}$ & 0.03276443 & 0.03940959 & 0.04935671 & 0.0527839 & 0.05993345 & 0.05132201 \\
\hline$S_{1 a}$ & 0.05608073 & 0.04473534 & 0.0387119 & 0.0335156 & 0.01195643 & 0.01648785 \\
\hline$S_{2}$ & 0.07656069 & 0.05218781 & 0.07008126 & 0.09860328 & 0.1180152 & 0.1209408 \\
\hline$S_{3}$ & 0.02037054 & 0.02098165 & 0.02151524 & 0.03776569 & 0.04631416 & 0.04392558 \\
\hline
\end{tabular}


Sherman. ${ }^{21}$ These measurements also differ from those made in reverberant rooms or wind tunnels since the sound transducers are not phase matched.

An alternative derivation of the one, two, and three dimensional spatial correlation relationships was made by Morrow $^{22}$ using the actual mode shapes of a rectangular room and some restrictive assumptions. He suggests that large deviations from the formula are possible if his assumptions are not met. Because one assumption is that the modal density is high and this is not true at low frequencies, the deviations observed using these standard spatial correlation models are not unexpected.

The results presented herein are not primarily an example of nonlinearities appearing in turbofan engine low frequency core noise. Instead, they are explained as being mainly due to an interference pattern caused by the spatial coherence of the sensor pair in the ambient core noise field. The interference pattern caused by the spatial coherence of a sensor pair in a diffuse noise field has been treated as part of reverberant room studies..$^{20,22-26}$ The literature on the spatial coherence of a sensor pair in the presence of turbofan core noise has a lacuna.

However, the results in the $25-50 \mathrm{~Hz}$ region where the peak sound occurs are in better agreement at the low power settings and in poor agreement at the high power settings. This might be attributed to some combination of nonlinear effects and spatial coherence effects not identified with the simple model discussed herein. However, the postcombustion residence time measured herein seems to indicate the source of the sound in the low frequencies is due to indirect combustion noise.

\section{CONCLUDING REMARKS}

The presence of coherent indirect and direct combustion noise in the core of this turbofan engine is observed. A low order model for the frequency response of the turbine to convected entropy and other disturbances moving at the flow velocity and direct combustion noise is successful in calculating the combustor/turbine exit pressure cross-spectral density from $0-400 \mathrm{~Hz}$ and the turbine exit pressure autospectrum from $0-100 \mathrm{~Hz}$ at all speeds. The ratio of direct combustion noise to indirect combustion noise is about 26 percent at the lowest power setting and then drops from 12 percent at 50 percent of maximum power to 5 percent at the maximum power setting.

An important result of the analysis of the turbine transfer function was development of a scheme to measure the post-combustion residence time in the combustor of a turbofan engine which might be useful in predicting or reducing thermal $\mathrm{NO}_{x}$ and soot. Also, a measurement of the postcombustion residence time in the combustor might be useful in measuring the relative health of a gas turbine engine or doing real time performance monitoring.

In order, to relate the transfer function model to the measurements studied, a spatial correlation function is developed for the enclosed ambient core noise field of the turbofan engine. Because proprietary geometry and flow information is not available, the approach used is based on an approximate analytical formulation. In addition, in this paper in order to study the enclosure sound field, the convective time delay observed in the combustor/turbine exit cross-spectrum phase is reduced by properly aligning the time histories. The cross-spectrum phase angle calculated after alignment is used because it reveals in more detail the interference pattern in the phase angle plots created by spatial correlation in the ambient sound field at low frequencies. The large scale structure interference pattern observed in the cross-spectrum phase angle measurements was replicated using this model. In addition, the model helps explain the measured noise reduction at low frequencies. The model shows this reduction is due to phase cancellation. The interference pattern can be observed in the crossspectrum phase measurement. An anisotropic pair of spatial correlation functions is used to model the ambient core noise spatial correlation function. The observed attenuation of the combustion noise shown is normally attributed to the turbine. The actual turbine attenuation is less by 2 to $6 \mathrm{~dB}$ or more at some frequencies because a large part of the attenuation measured is from destructive interference due to spatial correlation in the core noise sound field of the turbofan engine. The advance demonstrated here is that by providing an enclosure sound field based on spatial correlation in the engine core using an approximate analytical formulation the resulting model is in improved agreement with measured acoustic cross-spectra phase. As a result the acoustic linear system transfer function model between the combustion noise and the turbine exit noise was to some extent validated.

\section{ACKNOWLEDGMENTS}

The data used in this paper were provided with funding from the NASA Fundamental Aeronautics Subsonic Fixed Wing program. This work was supported by the NASA Glenn Research Center Fast Track Center Innovation Fund.

\section{APPENDIX: COST FUNCTION}

The cost function used is

$$
\begin{aligned}
C= & \left(S_{1} * 1000+S_{1 a} * 200+S_{2} * 800\right. \\
& \left.+S_{3} * 1000\right) / 201,
\end{aligned}
$$

where

$$
\begin{aligned}
& S_{1}=\sum_{f=0}^{f=250 \mathrm{~Hz}}\left[\frac{\phi_{9,10}^{\text {Aaligned }}(f)-\phi_{9,10}^{\mathrm{m}}(f)}{1000}\right]^{2}, \\
& S_{1 a}=\sum_{f=252}^{f=400 \mathrm{~Hz}}\left[\frac{\phi_{9,10}^{\mathrm{A} \text { aligned }}(f)-\phi_{9,10}^{\mathrm{m}}(f)}{1000}\right]^{2}, \\
& S_{2}=\sum_{f=0}^{f=390 \mathrm{~Hz}}\left[\frac{\log \left(\left|U(f)_{9,10}^{\mathrm{A}}\right|\right)-\log \left(\left|G(f)_{9,10}^{\mathrm{m}}\right|\right)}{10}\right]^{2},
\end{aligned}
$$




$$
S_{3}=\sum_{f=0}^{f=100 \mathrm{~Hz}}\left[\frac{\log \left(\left|G(f)_{10,10}^{\mathrm{A}}\right|\right)-\log \left(\left|G(f)_{10,10}^{\mathrm{m}}\right|\right)}{10}\right]^{2}
$$

and the phase angles are unwrapped.

The solution space is restricted by additional cost functions as follows:

$$
\begin{aligned}
& \zeta_{c 1}(f=0)<0, \\
& \zeta_{c 2}(f=0)<0, \\
& \epsilon_{1}: 0<\nu<1.0, \\
& \epsilon_{2}: \quad 10 \log (K)<-5, \\
& \epsilon_{3}: \quad 0<\tau_{T}<0.01, \\
& \epsilon_{4}: \quad 0<\tau_{p c}<5, \\
& \epsilon_{5}: \quad 0<\left|\varphi_{o}\right|<360, \\
& \epsilon_{6}: \quad-2<\left|\alpha \tau_{E}\right|<0, \\
& \epsilon_{7}: \quad \tau_{T E} \text { unrestricted, } \\
& \epsilon_{8}: \quad-2<\left|\alpha_{c 1}\right|<0, \\
& \epsilon_{9}: \quad \tau_{c 1} \text { unrestricted, } \\
& \epsilon_{10}: \quad\left|\vartheta_{c 1}\right|<360.0, \\
& \epsilon_{11}: \quad-2<\left|\alpha_{c 2}\right|<0, \\
& \epsilon_{12}: \quad \tau_{c 2} \text { unrestricted, } \\
& \epsilon_{13}: \quad\left|\vartheta_{c 2}\right|<360.0 .
\end{aligned}
$$

${ }^{1} \mathrm{M}$. Ihme and H. Pitsch, "On the generation of direct combustion noise in turbulent non-premixed flames,” Int. J. Aeroacoust. 11, 25-78 (2012).

${ }^{2}$ Y. Liu, A. P. Dowling, N. Swaminathan, T. D. Dunstan, R. Morvant, M. A. Macquisten, and L. F. Caracciolo, "Prediction of noise source for an aeroengine combustor," AIAA-2011-2913 (2011).

${ }^{3}$ N. A. Cumpsty, "Jet engine combustion noise: Pressure, entropy and vorticity perturbations produced by unsteady combustion or heat addition," J. Sound Vib. 66(4), 527-544 (1979).

${ }^{4}$ D. J. Bodony, "Scattering of an entropy disturbance into sound by a symmetric thin body," Phys. Fluids 21, 096101 (2009).

${ }^{5}$ F. E. Marble and S. M. Candel, "Acoustic disturbance from gas nonuniformities convected through a nozzle," J. Sound Vib. 55(2), 225-243 (1977).

${ }^{6} \mathrm{M}$. Leyko, F. Nicoud, and T. Poinsot, "Comparison of direct and indirect combustion noise mechanisms in a model combustor," AIAA J. 47(11), 2709-2716 (2009).

${ }^{7}$ M. S. Howe, "Indirect combustion noise," J. Fluid Mech. 659, 267-288 (2010).

${ }^{8}$ F. Bake, A. Fischer, N. Kings, and I. Röhle, "Investigation of the correlation of entropy waves and acoustic emission in combustion chambers," in Combustion Noise, edited by A. Schwarz and J. Janicka (Springer, Berlin, 2009), Chap. 5, pp. 125-146.

${ }^{9}$ A. Rausch, A. Fischer, H. Konie, A. Gaerlein, S. Nitsch, K. Knobloch, F. Bake, and I. Röhle, "Measurements of density pulsations in the outlet nozzle of a combustion chamber by Rayleigh-scattering searching entropy waves," J. Eng. Gas Turbines Power 133, 031601 (2011).

${ }^{10}$ J. Xu, C. K. W. Tam, and S. A. Parrish, "On indirect combustion noise," AIAA-2012-0543 (2012).
${ }^{11}$ W. Polifke, C. O. Paschereit, and K. Döbbeling, "Constructive and destructive interference of acoustic and entropy waves in a premixed combustor with a choked exit," Int. J. Acoust. Vib. 6(3), 135-146 (2001).

${ }^{12}$ J. H. Miles, "Aligned and unaligned coherence: A new diagnostic tool," AIAA Paper No. 2006-0010, Technical Report No. NASA/TM-2006214112, NASA, Cleveland, OH (2006).

${ }^{13} \mathrm{~J}$. H. Miles, "Estimation of signal coherence threshold and concealed spectral lines applied to detection of turbofan engine combustion noise," J. Acoust. Soc. Am. 129(5), 3068-3081 (2011).

${ }^{14} \mathrm{~J}$. H. Miles, "Time delay analysis of turbofan engine direct and indirect combustion noise sources," J. Propul. Power 25(1), 218-227 (2009).

${ }^{15}$ J. H. Miles, "Core noise diagnostics of turbofan engine noise using correlation and coherence functions," J. Propul. Power 26(2), 303-316 (2010).

${ }^{16} \mathrm{~J}$. H. Miles, "Separating direct and indirect turbofan engine combustion noise using the correlation function," J. Propul. Power 26(5), 1144-1152 (2010).

${ }^{17}$ J. H. Miles, "Separating direct and indirect turbofan engine combustion noise while estimating the post-combustion (post-flame) residence time using the correlation function," Technical Report NASA-TM-2011216248, NASA, Cleveland, OH (2011).

${ }^{18} \mathrm{~L}$. Hultgren and J. Miles, "Noise-source separation using internal and farfield sensors for a full-scale turbofan engine," AIAA Paper No. 2009-3220 Technical Report NASA/TM-2009-215834 NASA, Cleveland, OH (2009).

${ }^{19}$ L. S. Hultgren, "Full-scale turbofan-engine turbine-transfer function determination using three internal sensors," AIAA-2011-2912, Technical Report NASA-TM-2012-217252, NASA, Cleveland, OH (2011).

${ }^{20}$ R. K. Cook, R. V. Waterhouse, R. D. Berenot, S. Edelman, and J. M. C. Thompson, "Measurement of correlation coefficients in reverberant sound fields," J. Acoust. Soc. Am. 27(6), 1072-1077 (1955).

${ }^{21}$ B. F. Cron and C. H. Sherman, "Spatial-correlation functions for various noise models," J. Acoust. Soc. Am. 34(11), 1732-1736 (1962) [see also J. Acoust. Soc. Am. 38, 885(L) (1965)].

${ }^{22} \mathrm{C}$. T. Morrow, "Point-to-point correlation of sound pressures in reverberation chambers," J. Sound Vib. 16(1), 29-42 (1971).

${ }^{23}$ A. G. Piersol, "Use of coherence and phase data between two receivers in evaluation of noise environments," J. Sound Vib. 56(2), 215-228 (1978).

${ }^{24}$ J. S. Bendat and A. G. Piersol, Engineering Applications of Correlation and Spectral Analysis (Wiley, New York, 1980), pp. 167-175.

${ }^{25}$ A. G. Piersol, "Time delay estimation using phase," IEEE Trans. Acoust., Speech, Signal Process. 29(3), 471-477 (1981).

${ }^{26} \mathrm{H}$. Nélisse and J. Nicolas, "Characterization of a diffuse field in a reverberation room," J. Acoust. Soc. Am. 101(6), 3517-3524 (1997).

${ }^{27}$ J. R. Stone, E. A. Krejsa, and B. J. Clark, "Enhanced core noise modeling for turbofan engines," Technical Report No. NASA/CR-2011-217026, NASA, Cleveland, OH (2011).

${ }^{28}$ J. H. Miles, C. A. Wasserbauer, and E. A. Krejsa, "Cross spectra between temperature and pressure in a constant area duct downstream of a combustor," AIAA Paper No. 1983-0762, Technical Report NASA/TM83351, NASA, Cleveland, OH (1983).

${ }^{29}$ J. H. Miles, C. A. Wasserbauer, and E. Krejsa, "Cross spectra between pressure and temperature in a constant-area duct downstream of a hydrogen-fueled combustor," Technical Report NASA/TM-83463, NASA, Cleveland, OH (1983).

${ }^{30}$ L. Enghardt, A. Moreau, U. Tapken, and F. Kennepohl, "Radial mode decomposition in the outlet of a LP turbine-Estimation of the relative importance of broadband noise," AIAA Paper No. 2009-3286 (2009).

${ }^{31}$ D. V. Zante and E. Envia, "Simulation of turbine tone noise generation using a turbo-machinery aerodynamic solver," AIAA Paper No. 20093282 (2009).

${ }^{32}$ J. W. R. Griffiths, "The spectrum of compressor noise of a jet engine," J. Sound Vib. 1(2), 127-140 (1964).

${ }^{33}$ C. K. Sanathanan and J. Koerner, "Transfer function synthesis as a ratio of two complex polynomials," IEEE Trans. Autom. Control 8(1), 56-58 (1963).

${ }^{34}$ J. H. Miles, "Computer method for identification of boiler transfer functions," Technical Report No. NASA/TM-X-2436, NASA, Cleveland, $\mathrm{OH}$ (1971).

35."Engine validation of noise \& emission reduction technology phase 1," edited by D. S. Weir, Technical Report No. NASA/CR-2008-215225, NASA, Cleveland, OH, Honeywell Technical Report No. 21-12843A, Honeywell, Phoenix, AZ (2008), pp. 320-323, 430-433. 
${ }^{36} \mathrm{P}$. D. Welch, "The use of fast Fourier transform for the estimation of power spectra: A method based on time averaging over short, modified periodograms," IEEE Trans. Audio Electroacoust. 15(2), 70-73 (1967).

${ }^{37}$ S. D. Stearns and R. A. David, Signal Processing Algorithms using Fortran and $C$ (Prentice-Hall, Englewood Cliffs, NJ, 1993), pp. 48-50, 295-297.

${ }^{38}$ M. Schetzen, Linear Time Invariant Systems (Wiley-Interscience, New York, 2003), pp. 18, 244.
${ }^{39}$ M. J. D. Powell, "An efficient method of finding the minimum of a function of several variables without calculating derivatives," Comput. J. 7(2), 155-162 (1964)

${ }^{40}$ M. S. Shapiro and M. Goldstein, "A collection of mathematical computer routines," Technical Report NYU-1480-14, New York University (1965).

${ }^{41}$ J. L. Kuester and J. H. Mize, Optimization Techniques with Fortran (McGraw-Hill, New York, 1973), pp. 331-343. 